\title{
25. LA REFORMA DE LA CONSTITUCIÓN: OPCIONES CONSTITUCIONALES ANTE LA RATIFICACIÓN DE LOS ACUERDOS DE MAASTRICHT
}

UNIÓN POLÍTICA EUROPEA, DERECHOS DE LOS EXTRANJEROS Y REFORMA CONSTITUCIONAL: ANÁLISIS DEL CASO ESPAÑOL

JUAN FERNANDO LÓPEZ AGUILAR

Profesor Titular de Derecho Constitucional

Universidad de Granada 


\section{SUMARIO}

I. EL CASO ESPAÑOL: OPCIONES CONSTITUCIONALES.-II. LA OPCIÓN DE LA MUTACIÓN POR VÍA INTERPRETATIVA. - III. LA OPCIÓN DE LA REFORMA EXPRESA DE LA CONSTITUCIÓN: LA VIA DEL ART. 167 CE.-IV. CONCLUSIONES.-NOTA BIBLIOGRÁFICA. 


\title{
25. LA REFORMA DE LA CONSTITUCIÓN: OPCIONES CONSTITUCIONALES ANTE LA RATIFICACIÓN DE LOS ACUERDOS DE MAASTRICHT
}

\author{
UNIÓN POLÍTICA EUROPEA, DERECHOS DE LOS EXTRANJEROS \\ Y REFORMA CONSTITUCIONAL: ANÁLISIS DEL CASO ESPAÑOL
}

\author{
POR \\ JUAN FERNANDO LÓPEZ AGUILAR \\ Profesor Titular de Derecho Constitucional \\ Universidad de Granada
}

\section{EL CASO ESPAÑOL: OPCIONES CONSTITUCIONALES}

Prescindiré en esta Nota de abordar la tentadora problemática de reforma y revisión de la lex legum desde la contemporánea teoría constitucional, más o menos adecuada a las exigencias del Estado democrático de Derecho, modelo común al ámbito obligado de referencias comparadas. Por consiguiente, estas líneas quieren centrarse en exclusiva en el análisis de las perspectivas de reforma constitucional suscitadas por la ratificación por España del Tratado de Unión Europea.

Como en Francia y en Alemania, los problemas eventualmente planteables en España se concentran sobre todo en el capítulo atinente al reconocimiento de ciertos derechos políticos a ciudadanos no españoles de la futura Unión Europea (Arts. 8 a $8 \mathrm{C}$ ). En todo caso, revisten estimable importancia otros extremos contenidos en el Proyecto de Tratado destacando los artículos 6,1 a $7 \mathrm{C}, 8$ a $8 \mathrm{C}, \mathrm{J1}$ a $\mathrm{J11}, \mathrm{K}$ a $\mathrm{Kg}$, y Declaraciones n. ${ }^{\circ} 12,13,14,15,18,29,30$ y 31. 
En lo que nos concierne, la ratificación de un Tratado que importa el reconocimiento de los derechos de sufragio activo y pasivo a ciudadanos eurocomunitarios residentes en España, en elecciones directas al Parlamento Europeo y en las Municipales, plantea cuestiones jurídicas de diversa envergadura.

De entrada, la regulación del derecho al sufragio activo en las elecciones comunitarias excede ya de por sí el marco institucional del que responde el Estado: de este modo, las novaciones previstas en las Declaraciones 12, 13, 14, 15 y 18, incorporadas al Acta Final de la Conferencia de Maastricht, no supondrán problema constitucional alguno. Sí comportarán, en cambio, reforma de la LOREG (art. 210 a 227 de la L.O. 1/85 de 19 de junio), a la vista de lo dispuesto en el art. 138.3 del Proyecto de Tratado, encaminado a hacer posible la elección al Parlamento Europeo por sufragio universal directo con un procedimiento uniforme en todos los países miembros.

La concesión del derecho de voto a los extranjeros en elecciones comunitarias sí es, en cambio, dominio del legislador nacional. "En los términos que establezcan los Tratados y las leyes" (art. 13.1 CE), todos los extranjeros pueden asi disfrutar de los derechos y libertades del Título I CE (entre ellos, obviamente, los de participación) en el territorio español. Para con los ciudadanos eurocomunitarios residentes en España (un subsegmento especial del genérico «extranjeros»), tanto el art. 13.2 cuanto el art. 176.1 LOREG (L.O. 1/85, de 19 de junio) contemplan la concesión del derecho al sufragio activo en las municipales mediando tratado a ese propósito y lógicamente en condiciones de reciprocidad.

A partir de estas coordenadas, el problema se plantea con el sufragio pasivo en las municipales (art. 8.1.b) del Tratado de la Unión). Es este punto el que plantea no sólo muy serios visos de abonar la reforma de la Constitución, sino una ocasión para un debate de uideas de la Constitución" en que se pone de relieve la aplicabilidad en nuestro suelo y en nuestro ordenamiento de ciertas premisas teóricas relativas a las polémicas de la mutación constitucional.

\section{LA OPCIÓN DE LA MUTACIÓN POR VIAA INTERPRETATIVA}

En efecto, un mismo orden constitucional propicia diversas lecturas sobre su elasticidad y sobre la procedibilidad de los cauces de reforma previstos en el Título X: partiendo de la mutación por vía interpretati- 
va, llegando a la vía agravada del art. $168 \mathrm{CE}$, y pasando por la vía menos rígida de reforma explícita del art. 167, se ha hecho sentir un claro espacio para la argumentación.

Abriendo el debate a este respecto, y a requerimiento del Gobierno, un Dictamen de la Comisión Permanente del Consejo de Estado fechado en 20 de junio de 1991 abordó en su momento las previsibles cuestiones constitucionales que podrían suscitarse a raíz del reconocimiento de los derechos de sufragio activo y pasivo a los ciudadanos comunitarios en el Estado miembro en el que residan.

En la medida en que este Dictamen apuesta decididamente por la posibilidad de abordar enteramente los contenidos de Maastricht sin necesidad de abordar una reforma expresa de la Constitución, este posicionamiento doctrinal nos proporciona un primer punto de apoyo a los efectos planteados en la presente Nota. En efecto, una polémica ya preceptible entre nosotros viene poniendo de relieve la pluralidad de enfoques que la cuestión recibe, primero en lo relativo a la necesidad o no de la reforma misma, $y$, segundo, en lo relativo al mecanismo técnico por el que solventar las exigencias jurídicas de recepción de Maastricht. Vamos a analizar las diferentes opciones.

De entrada, para situarnos, los artículos constitucionales de referencia comprenden: art. 23 (participación política de los ciudadanos); art. 13.2 (derecho de los extranjeros al sufragio activo en elecciones municipales, en condiciones de reciprocidad); art. 93 (atribución de competencias derivadas de la Constitución a instituciones de carácter supranacional mediante ley orgánica); art. 95 (revisión constitucional previa a la celebración de Tratado internacional contrario a la Constitución); artículos 166 a 169 (reforma y revisión constitucionales).

En el citado Dictamen, el Consejo de Estado se pronunció exclusivamente sobre la eventual extensión del derecho de sufragio a los extranjeros nacionales de Estado comunitario en las elecciones al Parlamento Europeo y en las municipales; no así en las elecciones generales ni en las de ámbito autonómico.

La razón de este principio de limitación objetiva es fácilmente comprensible. En relación con el régimen del sufragio activo y pasivo de cara a las elecciones al Parlamento Europeo, no se plantea, en efecto, ningún problema de constitucionalidad. El Parlamento Europeo es una institución eurocomunitaria, cuyo régimen jurídico responde íntegramente a los dictados y principios del propio sistema de fuentes eurocomunitario. La Comunidad Europea conforma un verdadero ordenamiento jurídico autóno- 
mo, caracterizado por el rasgo de la supranacionalidad (primacía, eficacia directa y aplicación uniforme). Los elementos constitutivos de sus Instituciones trascienden, por tanto, a las competencias normativas de los Estados Miembros, en virtud de la cesión de atribuciones lo de los denominados "ámbitos de soberanía" que ha sido operada a través de cláusulas como la contemplada en el art. 93 de la CE.

Por eso mismo, la extensión del derecho de sufragio al Parlamento Europeo ni siquiera representa, en la argumentación suscrita por el Consejo de Estado, una nueva transferencia de "competencias derivadas de la Constitución" (art. $93 \mathrm{CE}$ ). Se trataría, por el contrario, de un Tratado de carácter estrictamente político, bajo la cobertura del art. $94 \mathrm{CE}$, que exige exclusivamente la previa autorización de las Cortes Generales, por mayoría simple, para su ratificación.

Problema distinto lo presenta el reconocimiento, en virtud de una reforma del Tratado CEE (Roma, 1957), del derecho de sufragio activo en las elecciones municipales. El art. 13.2 de la Constitución pasa a imponer una lectura restrictiva de esta posibilidad cuando señala que «solamente los españoles serán titulares de los derechos reconocidos en el artículo 23, salvo lo que, atendiendo a criterios de reciprocidad, pueda establecerse por Tratado o Ley para el derecho de sufragio activo en las municipales".

El ordenamiento jurídico comunitario constituye, como acaba de recordarse, un sistema de Derecho autónomo y dotado de mecanismos propios de desarrollo normativo e integración. Su evolución evidencia la gran flexibilidad con la que ha venido absorbiendo desde su ideación espacios competenciales no explícitamente previstos, en principio, por las disposiciones textuales del denominado Derecho Comunitario originario (básicamente los Tratados de París, de Roma y el Acta Única de 1986), lo cual es, por lo demás, un rasgo común y arquetípico de todas las experiencias protofederalizantes, tal y como evidencia la vis expansiva advertida en la Commerce Clause del art. I.8.18 de la Constitución de los EE.UU de 1787. El reconocimiento, por revisión de los Tratados Constitutivos de las Comunidades, del derecho de sufragio activo en las elecciones municipales a todos los ciudadanos comunitarios, siempre en los Estados Miembros en que residan, resultaría, pues, perfectamente encajable dentro de la previsión del art. 13.2 CE.

La adopción de un Tratado con tal estipulación no representaría por tanto, a juicio del Consejo de Estado, una verdadera transferencia de "competencias derivadas de la Constitución». Se trataría solamente de un Tratado internacional que, con carácter político (94.1.a CE), afectaría a los 
derechos del Título I CE (94.1.b), por lo que su ratificación sólo exigiría su previa autorización por las Cortes Generales (art. 94.1. CE).

Frente a la argumentación sostenida por el Consejo de Estado puede, no obstante, objetarse que, en la medida en que las dos previsiones que se acaba de exponer entrañan una reforma expresa de los Tratados constitutivos de la Comunidad Europea, sólo podrían ser autorizados en virtud de la adopción de una nueva ley orgánica de acuerdo con el art. $93 \mathrm{CE}$. Tal fue, además, la vía por la que se autorizó anteriormente la ratificación por España del Acta Única Europea (LO 4/86, de 26 de noviembre), expresión ésta igualmente del "proceso de profundización» de los objetivos inherentes a la integración europea.

Pero, una vez cubierta esta primera cuestión, el reconocimiento del derecho de sufragio pasivo para esas mismas elecciones municipales en España sí plantearía, en cualquier caso, una valoración mucho más delicada.

Para abordarla, el Consejo de Estado recurrió a las socorridas "potencialidades no agotadas" de los arts. 93, 94 y $95 \mathrm{CE}$, en su juego combinado.

Sin duda, el 93 CE permite la atribución a instancias supranacionales de potestades que la propia Constitución ha conferido a los órganos poderes contemplados en ella. Pero esa posibilidad de modificar expresamente la propia Constitución (esto es, sorteando las disposiciones del Título $X \mathrm{CE}$, de notable rigidez) no son absolutamente limitadas: en el caso de afectar el régimen sustantivo de los derechos y libertades reconocidos en la Sección Primera del Capítulo II del Título I CE (así como el Título Preliminar y el Título II, de la Corona) resultaría inobviable el recurso al procedimiento de rigidez reforzada del art. $168 \mathrm{CE}$.

No ha parecido ser éste el supuesto de referencia: el artículo afectado no es en rigor el 23, sino, exclusivamente, el 13.2 CE. Además, tal afectación no concierne en pluralidad al contenido del derecho, sino exclusivamente a un aspecto -el sufragio pasivo- del régimen de la organización municipal española.

Partiendo de esta base, el Consejo de Estado ha sostenido la tesis de que, tanto en atención a las potencialidades del art. 93 cuanto a la flexibilidad con que en los ordenamientos constitucionales europeos se ha procedido a asumir la capacidad innovadora del sistema de Derecho eurocomunitario, resulta, además, posible eludir la rigidez de la denomi- 
nada «reforma parcial» de la CE (art. 167), dado que no se afectaría al ámbito material expresamente protegido por la citada rigidez.

En efecto, el art. 13.2 no se encuentra ni en el Título Preliminar ni en la Secc. 1 del Capítulo II del Título I CE. Este precepto no se refiere al contenido esencial de los derechos reconocidos en el art. 23, sino, exclusivamente al círculo de sujetos titulares de tales derechos. En la tesis del Consejo de Estado, la restricción operada en el art. 13.2 responde a un pronunciamiento sobre organización política, pero no sobre los contenidos nucleares inherentes al reconocimiento de un derecho fundamental como son los que, por su parte, y en diferente sede, contempla el art. 23.

Además los principios rectores de la organización municipal española no aparecen en el Título Preliminar de la Constitución ni en la referida Secc. 1, Cap I, Tít. I CE. De este modo, el reconocimiento, en un Tratado de Unión Política, (en revisión del TCEE 1957), del derecho de sufragio pasivo en elecciones municipales a ciudadanos de esa Unión de orden supranacional no afectaría a los derechos del art. $23 \mathrm{CE}$, como tampoco al Título Preliminar. El esfuerzo interpretativo que exige la absorción, por el ordenamiento constitucional español, de la profundización de la integración eurocomunitaria - proceso éste fundado en las disposiciones institutivas, orgánicas y de programación final que constituyen el núcleo del Derecho comunitario- debería así, abrir la puerta a una extensión de los derechos de sufragio titulados por ciudadanos de la Comunidad sin necesidad de acudir a la reforma constitucional, sobre la base que aportan las potencialidades del art. $93 \mathrm{CE}$.

Sin duda, la argumentación sostenida en el Dictamen del Consejo de Estado presenta aspectos discutibles, guiada como aparece por la voluntad de servir, con todos los instrumentos disponibles, a las exigencias estructurales y a los principios básicos del ordenamiento jurídico-comunitario. A pesar de ello, siempre será posible contraargumentar la incompatibilidad del tenor literal del vigente art. 13.2 CE con el reconocimiento de sufragio activo al extranjero, por más que sea éste ciudadano de la Comunidad. En ese caso, lo que sí resulta cierto es que no será nunca necesaria la vía super-reforzada del $168 \mathrm{CE}$. Podrá optarse por la reforma parcial de la Constitución contemplada en el $167 \mathrm{CE}$ : no se exigirá en ningún caso disolución de las Cámaras; sólo procederá referéndum si así lo solicitara la décima parte de una de las Cámaras; la mayoria requerida será la de los $3 / 5$, pudiendo evitarse ésta si, dándose la mayoría absoluta en el Senado, se obtuviera mayoría de $2 / 3$ en el Congreso.

Advertiremos finalmente cómo el Consejo de Estado no dejaría de recordar el mecanismo contemplado por el art. 95.2 CE: el TC, intérprete 
supremo de la Constitución, podrá ser instado (por el Gobierno o por cualquiera de las Cámaras) a pronunciarse, con carácter previo a la ratificación por España de un Tratado internacional, sobre la eventual existencia de contradicción entre éste y la Ley Fundamental (art. 78 LOTC).

En consecuencia, pues, y resumiendo los ejes argumentativos de esta primera opción a la que denominaríamos "mutación por vía interpretativa" cabe afirmar, en primer término, que las estipulaciones de un Tratado de Unión Política que reconozca a los ciudadanos de los Estados Miembros el derecho de sufragio activo y pasivo en España de cara a las elecciones al Parlamento Europea tendría el carácter político a que ser refiere el art. 94.1.a CE. No presenta ningún problema de constitucionalidad. El mismo carácter tendría, en segundo lugar, el reconocimiento del sufragio activo en las elecciones municipales a los ciudadanos de la Unión residentes en España. En fin, y en tercer lugar, el reconocimiento, para este último supuesto, del derecho del sufragio pasivo, podría lícitamente autorizarse por medio de una Ley Orgánica al amparo del artículo $93 \mathrm{CE}$.

No se agotan, sin embargo, con esto ni las posiciones desde las que cabe apelar a la argumentación de la umutación por la vía de la interpretación constitucional" ni las posiciones desde las cuales cabe apelar sencillamente a una operación de reforma constitucional expresa.

En efecto, aun conviniendo que el reconocimiento de los derechos de sufragio activo y pasivo a los ciudadanos de la Comunidad existentes en España para las elecciones al Parlamento Europeo no plantea ningún problema de constitucionalidad (pues las Cortes Generales pueden autorizar la ratificación de este punto sin obstáculo jurídico), el derecho de sufragio para las elecciones municipales es un problema muy distinto al de la organización de una institución par excellence eurocomunitaria como es el Parlamento Europeo de Estrasburgo.

En cuanto al sufragio activo, resulta perfectamente encajable en el dictado del art. 13.3 CE (derechos de los extranjeros en España) en conexión con el del art. 23 (derechos de participación política sólo a los españoles). Cosa diversa, desde luego, es el sufragio pasivo (derecho a ser elegibles) en esas elecciones locales.

Tal reconocimiento podría contradecir el tenor literal del artículo 13.2 ( «... salvo lo que pueda establecerse para el derecho de sufragio activo en las elecciones municipales").

El Consejo de Estado sostiene, como hemos visto, que sí resulta 
constitucionalmente posible tal extensión del sufragio, apurando las posibilidades interpretativas del 93 CE («mediante Ley Orgánica se podrán autorizar (...) Tratados por los que se atribuya (a una institución supranacional) el ejercicio de competencias derivadas de la Constitución"), con base en los siguientes argumentos:

a) Tal extensión no afectaría el 23 CE (derecho fundamental de participación, reconocido sólo a los españoles), sino al 13.2 CE.

b) En caso de que esa extensión comportase una modificación de la Constitución (Título $X \mathrm{CE}$ ), no procedería en ningún caso recurrir al 168 CEE (ureforma agravada", con disolución de las Cortes y referéndum obligatorio después de su aprobación por $2 / 3$ en cada Cámara), sino sólo al 167 ("reforma ordinaria», por las Cortes Generales, sin disolución y sin necesidad de referendum).

Hay en ello un argumento en el que resulta difícil no estar de acuerdo con el Consejo de Estado: el 168 resulta sólo necesario para modificar directamente el Título Preliminar, la Sec. 1 del Cap. II del Tít. I CE (derechos fundamentales) y el Tít. II (la Corona). El 13.2 CE escapa al Cap. II (Derechos y Libertades): pertenece al Cap. I (españoles y extranjeros), por lo que, en el peor de los casos, afectaría solamente al 167: (Reforma menos rígida: aprobación por $3 / 5$ por cada Cámara, e incluso con mayoría absoluta en el Senado si se consiguen $2 / 3$ en el Congreso. Sólo procederá referéndum si lo solicita la décima parte de los miembros de una Cámara).

El Consejo de Estado no explica bien, sin embargo, por qué una Ley Orgánica del $93 \mathrm{CE}$ permitiria evitar también la reforma ordinaria del 1.67 CE. Este artículo permite "atribuir el ejercicio de competencias derivadas de la Constitución" a las instituciones eurocomunitarias. Pero la concesión del derecho de sufragio pasivo a los ciudadanos europeos en España no es, en rigor, "atribución de competencias", sino modificación de un precepto sustantivo de la CE (artículo 13.2).

Este punto sí presenta, por lo tanto, una dificultad objetiva manifiesta: por más que se "estire" por vía interpretativa la lectura del artículo 93, habría que admitir la posible necesidad de apelar a la reforma ordinaria del 167, vía que tiene la ventaja de resultar competencia de las Cortes Generales (no hay que disolver las Cámaras ni convocar referéndum).

Podría argumentarse, sin embargo, y por apurar la argumentación 
en favor de la vía del $93 \mathrm{CE}$, que por una Ley Orgánica de las previstas en este artículo sería posible atribuir a la Comunidad Europea (en virtud del peculiar carácter supranacional de su ordenamiento jurídico) la competencia que el 167 CE reserva a las Cortes Generales: esto es, "modificar» el contenido del artículo 13.2 CE, sin necesidad de modificar la letra de dicho artículo por la vía de una reforma constitucional expresa.

Teniendo en cuenta, además, las exigencias del proceso de integración europea, esta interpretación parece a primera vista jurídica y dialécticamente defendible. Pero no definitiva. Viene a jugar, en todo caso, con una doble ambigüedad en la Constitución:

a) No está claro el alcance potencial del 93 CE («atribución de competencias derivadas de la Constitución»), especialmente cuando hablamos de una institución supranacional como es la Comunidad Europea (principios de primacia, efecto directo $y$ aplicación uniforme de su acervo juridico propio).

b) El $167 \mathrm{CE}$ plantea una reforma parcial que puede ser instrumentada por las Cortes Generales sin excesivos problemas (mayoria de $3 / 5)$. Si se entiende que la competencia para adoptar leyes de reforma constitucional parcial (no "total", en el sentido del 168, mucho más complicadas) se encuentra también a cubierto del $93 \mathrm{CE}$-en cuanto podría permitir atribuir a organizaciones internacionales la propia competencia de modificación constitucional que el 167 reserva a las Cortes-, el problema desaparecería: podría ratificarse el Tratado por vía de Ley Orgánica, sin modificación expresa de la Constitución (tal y como sostiene el propio Consejo de Estado).

Ello no impide advertir la paradoja que plantea el que para que un acto juridico supranacional pudiese comportar alteraciones parciales de la Constitución sólo haga falta Ley Orgánica (mayoría absoluta en el Congresol, mientras que para obtener ese mismo resultado a través de los órganos constitucionales internos sea precisa su aprobación por mayorías de $3 / 5$ en cada Cámara (o la aún mayor de 2/3 en el Congreso de los Diputados, siempre que se haya obtenido mayoría absoluta en el Senado: art. $167 \mathrm{CE})$.

La cuestión, como se ve, es sumamente problemática. El Consejo de Estado opina que puede hacerse. La doctrina, sin embargo, comienza a mostrar divisiones, en torno a las tres opciones escrutadas hasta ahora: la de mutación por vía interpretativa (A. MANGAS, J. DE MIGUEL, del 
lado, en general, de la doctrina más "comunitarista»); la de la necesidad de reforma por la vía del 167 CE (J. PÉREZ ROYO; M. MARTÍNEZ CUADRADO); y la de necesidad de la reforma por la vía del $168 \mathrm{CE}$ (J. DE ESTEBAN).

En efecto, aun cuando, por lo apremiante de toda "primera lectura", es evidente que no contamos todavía con un tratamiento doctrinal que haya cubierto extensamente los problemas aquí expuestos, sí se han avanzado en cambio algunos pronunciamientos en vía preliminar (principalmente a través de artículos de prensa y conferencias provistas de una cierta difusión).

Así, en la línea de la mutación interpretativa convergerá un tercer recurso argumentativo: el que supondría reformar en exclusiva la LOREG (arts. 6 y 177) para extender la cobertura de la unacionalidad españolan a los residentes comunitarios a los efectos contemplados en los arts. 23 y 13.2 CE, en combinación con los artículos 176 y ss. LOREG (relativos a las elecciones municipales), y con los artículos del Código Civil reguladores del estatuto de la nacionalidad española. Todo ello, por lo tanto, dejando intocado el texto de la Constitución.

\section{LA OPCIÓN DE LA REFORMA EXPRESA DE LA CONSTITUCIÓN: LA VÍA DEL ART. 167 CE}

Por su parte, en la línea de la apertura a la reforma por la vía menos agravada del art. 167 militarían quienes opinan que la noción de "ciudadano" del art. 23.1 CE puede ser integrada legislativamente sin reformar la Sección $1 .^{\text {a }}$ del Capítulo II del Título I CE (arts. 15 a 29); no así la noción de "españoles" que se desprende del art. 13.2 CE. Este precepto, sin embargo, será susceptible de reforma en trámite exclusivamente parlamentario, si así lo apoyase el consenso que en cuestiones europeas ha sido hasta ahora usual en las Cortes Generales: no se haria necesaria, por tanto, ni la previa disolución de las Cortes ni la posterior convocatoria de un referéndum de ratificación.

En todo caso y a la vista de la enjundia y mérito de la cuestión, la solución más segura la ofrecerá siempre el mecanismo contemplado expresamente en el artículo 95.2 CE y desarrollado en el Título VI de la LOTC: el Tribunal Constitucional podrá ser instado por el Gobierno o por cualquiera de las Cámaras a pronunciarse sobre la posible contradicción 
con la Constitución de un Tratado, con carácter previo a su definitiva ratificación por España.

Además de agotar las posibilidades de "ajuste" constitucional de la previsión relativa al sufragio pasivo de los ciudadanos europeos en las municipales, la declaración del Tribunal Constitucional proporcionará, en última instancia, un razonable fundamento jurídico-constitucional a una eventual iniciativa de reforma de la $\mathrm{CE}$, en modo que resultase comprensible y aceptable por todos.

Por lo demás, estimamos que pueden caber pocas dudas de que la ocasión se presenta difícilmente mejorable para estrenar a este propósito una competencia que ha sido reconocida al TC por el constituyente, en una dimensión además que no siempre resulta suficientemente subrayada: la de custodia objetiva de la constitucionalidad del ordenamiento todo, más allá de la resolución y/o reintegración de situaciones jurídicas en los diferentes conflictos intersubjetivos planteables.

\section{CONCLUSIONES}

Una Constitución no es, como se ha repetido hasta la saciedad, un texto sagrado e inamovible. Es, sin duda, un instrumento -incluso el más eficaz- para la consecución del marco jurídico estable para la convivencia y para la organización de los procesos colectivos. En cuanto Norma Suprema, cualificada a menudo por los rasgos adyacentes de la supralegalidad y la supremacía material o sustantiva, la Constitución se presenta, de una u otra manera, provista de cierta rigidez o dificultad formal de modificación.

Ningún otro panorama hubiera resultado lógico en un caso como el español, en el que la Constitución se erige como Norma fundacional de un Estado de Derecho, directamente vinculante para los poderes públicos y para los ciudadanos, como producto de un pacto cuidadosamente elaborado. Lógica ha sido por lo tanto la tendencia a la autocontención de prontos revisionismos por parte de la doctrina. Y lógica también, por los mismos motivos, la pauta mutacional operada en el registro de sus instituciones y su sistema de fuentes al hilo de los cambios habidos en sus años de vigencia. De hecho, como se ha apuntado, la hiper-rigidez que adjetiva al Título X CE (especialmente en sus arts. 167 y 168) se asocia no infrecuentemente a una necesaria dosis de elasticidad. Este rasgo ha dado frutos notables en la ordenación territorial del poder, así como en la 
prestación de las fuentes normativas (esto es, la "irrupción" de los actos eurocomunitarios en el sistema de fuentes constitucionalizado).

Problema más delicado lo presenta la modificación del régimen sustantivo del disfrute de derechos y libertades constitucionales. La Constitución ofrece un amplio margen de actuación para lo que se ha llamado «legislador de desarrollo de los derechos fundamentales». Muchas de estas variaciones no afectan, pues, en lo más mínimo a la pervivencia intocada del texto constitucional. Otras parecen, en cambio, prestarse mejor a la polémica, al debate doctrinal: así, la noción de "flagrancia" del art. 18.2 CE; asi, igualmente, las bases del régimen de extradición pasiva del artículo 13.3 CE, del asilo en el art. 13.4 CE conforme a las innovaciones que plantea el sistema Schengen, o del sufragio pasivo para los extranjeros en el art. 13.2 CE, según la innovación planteada en el art. 8.6.1 del Tratado de la Unión.

En congruencia con cuanto se ha expuesto, el expediente más solvente no puede ser otro que el previsto en el art. 95.2 CE: una consulta al $\mathrm{TC}$, en sede previa a la celebración de un tratado internacional que contenga estipulaciones cuya posible contradicción con la Constitución exija su previa reforma.

Técnica ésta conocida en el Derecho Comparado (notablemente, en el art. 54 de la CFr de 1958), plantea, en nuestro ordenamiento, algunos problemas teóricos. Así: a) -la ubicación de la misma en el Capítulo II del Título III CE relativo a las Cortes Generales y a sus competencias respecto a tratados internacionales, y no el Título IX, relativo cabalmente al propio $\mathrm{TC} ; b)$-su cohonestación con las técnicas para la ratificación de varios tipos de Tratados en el art. 94.1 CE: "políticos", "militares", "que afecten a los derechos $y$ deberes fundamentales" del Título I CE, "que supongan modificación o derogación de alguna ley o exijan medidas legislativas para su ejecución"; c) -la utilización por el art. 95.1. CE de una fórmula textual - la exigencia de una previa "revisión constitucional»no coincidente con la idea de "reforma" y "revisión» que se desprende de los arts. 167 y $168 \mathrm{CE}$.

Pero suscita, sobre todo, problemas de carácter práctico:

a) La indeterminación constitucional sobre la conjugación del procedimiento previsto en el Título $X$ CE respecto de lo señalado en el art. 95:

«1. La celebración de un tratado internacional que contenga estipulaciones contrarias a la Constitución exigirá la previa revisión constitucional. 
2. El Gobierno o cualquiera de las Cámaras puede requerir al Tribunal Constitucional para que declare si existe o no esa contradicción".

b) Su desarrollo en la LO 2/79, de 3 de octubre, del TC:

Art. 2.1.e): "De la declaración sobre la constitucionalidad de los tratados internacionales».

Art. 10.d): "Del control previo de constitucionalidad».

Art. 27.1.c): "Los tratados internacionales". (Lo cual indica que no sólo en sede de consulta previa puede ser declarada su inconstitucionalidad, sino también de conformidad a las disposiciones genéricas contempladas en los arts. 27 a 40 LOTC, y, en particular, en cuanto a legitimación, en el 32.1 LOTC.)

Art. 78:

"1. El Gobierno o cualquiera de ambas Cámaras podrán requerir al Tribunal Constitucional para que se pronuncie sobre la existencia o inexistencia de contradicción entre la Constitución y las estipulaciones de un tratado internacional cuyo texto estuviera ya definitivamente fijado, pero al que no se hubiere presentado aún el consentimiento del Estado.

2. Recibido el requerimiento, el Tribunal Constitucional emplazará al solicitante y a los restantes órganos legitimados, según lo previsto en el apartado anterior, a fin de que, en el término de un mes, expresen su opinión fundada sobre la cuestión. Dentro del mes siguiente al transcurso de este plazo y salvo lo dispuesto en el apartado siguiente, el Tribunal Constitucional emitirá su declaración que, de acuerdo con lo establecido en el artículo 95 de la Constitución, tendrá carácter vinculante.

3. En cualquier momento podrá el Tribunal Constitucional solicitar de los órganos mencionados en el apartado anterior o de otras personas físicas o jurídicas $u$ otros órganos del Estado o de las Comunidades Autónomas, cuantas aclaraciones, ampliaciones o precisiones estimen necesarias, alargando el plazo de un mes antes citado en el mismo tiempo que hubiese concedido para responder a sus consultas, que no podrá exceder de treinta días». (Único artículo del Título VI LOTC, sobre la declaración previa o la ratificación, redactado conforme a la LO 4/85, de 7 de junio.) 
c) Su desarrollo en los vigentes Reglamentos parlamentarios: arts. 157 RCD de 10 de febrero de 1982 (iniciativa: el Gobierno; dos Grupos Parlamentarios; $1 / 5$ de los Diputados. Aprobación: mayoría simple) y 147 RS, de 26 de mayo de 1982 (iniciativa: un Grupo Parlamentario o 25 Senadores; aprobación: mayoría simple).

Desde el punto de vista político, aquí como en Francia o Alemania el dictamen del TC (-en rigor, declaración de no conformidad con la CE-) asienta, de entrada, un punto firme más allá de los debates y posicionamientos polémicos. De acuerdo con el axioma que inmejorablemente expresara la decisión del Justice Jackson en su USSCt Brown vs. Allen («lt is not that we are final simply because we are infallible; it is rather that we are infallible just because we are final"), sólo el TC tiene en sus manos la potestad de aclarar la necesidad de abordar reformas constitucionales con ocasión de Maastricht (el art. 8.b.1 en relación con el art. 13.2 CE); sólo el TC puede apuntar de modo definitivo el alcance de las mismas y el arco de opciones técnicas que se ofrecen para ello.

En los niveles paideico, simbólico o de "cultura" y "sentimiento constitucional", la apertura de este proceso surtiría además el importante efecto colateral de desactivar el conjuro de intangibilidad cuasi-sacramental que ha revestido hasta ahora nuestra Ley de leyes.

Compete al TC, en todo caso, sentar la última palabra. Su jurisdicción, rogada, habrá de ser activada, en sede previa a la rectificación, de conformidad a lo previsto en los arts. 95.2 CE, 78 LOTC $y$, alternativa o conjuntamente, 157 RCD y 147 RS. En carácter posterior a la rectificación, podrá, teóricamente, ser objeto de sentencia por la vía de los procedimientos contemplados en el Título II de la LOTC (arts. 27 a 40: el recurso y la cuestión).

Por último, y al margen ya del análisis constitucional, no convendría ignorar la salida alternativa a los problemas tratados a lo largo de esta Nota que ha sido abierta por el propio art. 8.b.1 (in fine) del Tratado de la Unión. Reza, literalmente: "Este derecho (el de sufragio activo y pasivo del residente eurocomunitario en elecciones municipales en cada Estado Miembro) se ejercerá sin perjuicio de las modalidades que el Consejo deberá adoptar antes del 31 de diciembre de 1994, por unanimidad, a propuesta de la Comisión y previa consulta al Parlamento Europeo. Dichas disposiciones podrán establecer excepciones cuando así lo justifiquen problemas específicos de un Estado Miembro». 


\section{NOTA BIBLIOGRÁFICA}

Los clásicos colacionados en las primeras líneas comprenden las siguientes referencias obligadas: E. SIÉYES: Escritos y discursos de la Revolución. Madrid, CEC, 1990; Lord BRYCE: Constituciones flexibles y Constituciones rigidas. Madrid, IEP, 1963; G.F. JELLINE K.: Reforma constitucional y poder constituyente. Madrid, CEC, 1991.

Ya en el siglo $x X$, aportaciones importantes a la teoría del poder constituyente y de sus implicaciones sobre las problemáticas de revisión y reforma han sido suscritas por C. ScHMITT: Teoría de la Constitución. Madrid, Al. Ed., 1982; M. GarcíA-Pelayo: Derecho Constitucional comparado. Madrid, 1950; C. MORTATI: "Concetto, limiti e procedimento della revisione della Constituzione", en Riv. Diritto Pubblico, 1952; K. LoEWEnSTEIN: Teoría de la Constitución. Barcelona, Ariel, 1983; S. BARILE: "Potere costituente", en AA.VV: Novissimo Digesto, vol. XIII, Torino, 1966, y, sobre todo, K. HESSE: Escritos de Derecho Constitucional (Comp. y trad: P. Cruz Villalón), Madrid, CEC, 1983.

Para una revisión de los distintos patrones de rigidez constitucional en el entorno comparado del Estado de Derecho de cuño demoliberal, Cfr. G. de VergotTINI: Derecho Constitucional comparado. Madrid, EspasaCalpe, 1983; P. BISCARETTI DI RUFFIA: Diritto Costituzionale comparato, Milano Giuffré, 1984.

En la doctrina española, y ya en relación con los arts. 166-169 de la Constitución Española de 1978, pueden consultarse los trabajos de M. Contreras ("La Reforma de la Constitución», en AA.VV: Estudios sobre la Constitución Española de 1978. Zaragoza, Ed. M. RAMirez, 1979); J. JIMÉNEZ CAMPO ("Algunos problemas de interpretación en torno al Título $X$ de la Constitución", en RDPol, n. 7 , UNED, otoño 1980); J. PÉrez-Royo ("Algunas reflexiones sobre el Título $X$ de la Constitución», en $R$. Política Comparada. Madrid, UIMP, 1984).

Dentro del mismo contexto de la Constitución de 1978, las monografías clave publicadas hasta ahora continúan siendo las firmadas por los Profs. P. DE VEGA (La Reforma Constitucional y la problemática del poder Constituyente. Madrid, T-Clave, Tecnos, 1985), y J. Pérez-Royo (La reforma de la Constitución. Madrid, CD, 1987).

Por su parte, los problemas que para la integración del ordenamiento constitucional supone la recepción de fuentes de origen supranacional pueden ser explorados en los trabajos de J. DE Miguel ZARAGOZA ( «Problemas constitucionales en la recepción del Derecho Derivado Co- 
munitario", BIMJ, n. ${ }^{\circ} 1184,1979$ ); A. MANGAS ("La recepción del Derecho Español de los actos normativos de las instituciones comunitarias", en AA.Vv: Constitución, CC.AA. y Derecho Internacional. Madrid, 1982, y Derecho comunitario europeo y Derecho español. Madrid, Tecnos, 1986); M. Medina ( Problemas constitucionales en la adhesión de España a la CEE», en M. Diez DE Velasco (Comp): El Derecho de la CEE. Madrid, 1982), y G. GARzón (apud alii): "La aplicación del Derecho Comunitario en España y las competencias de las CC.AA», en AA.VV: La aplicación del Derecho de la CE por los organismos subestatales. Barcelona, 1986. Desde una perspectiva más centrada en la lectura ordinamental de la CE que propiamente en el impacto del acquis communitaire, pueden ser consultadas las contribuciones de F. RUBIo ("El bloque de constitucionalidad»), L. PAREJO ("Constitución y valores del ordenamiento»), L. I. SÁNCHEZ-ROdRíGUEZ («EI artículo 93 y el bloque de la constitucionalidad: algunos problemas») y J. A. CARRILlo ( Funciones del Derecho Internacional contemporáneo: garantía de la independencia de los Estados e instrumento para la cooperación entre los Estados") al Tomo I de la obra de AA.VV: Estudios sobre la Constitución Española de 1978 en Homenaje al Profesor E. García de Enterría. Madrid, Civitas, 1991.

En cuanto al efecto operado por la jurisprudencia del TJCEE de Luxemburgo sobre las garantías del acervo de derechos y de libertades públicas común a la tradición democonstitucional europea, véanse dos trabajos publicados en la REDC, I. LASAGABASTER: "Las Comunidades Europeas y los derechos fundamentales", en REDC, n. ${ }^{\circ} 18,1986$, y L. M. DízZPICAZO: "¿Una Constitución sin declaración de derechos?", REDC, n. ${ }^{\circ} 32$, 1991, así como los artículos y bibliografía allí citados. Sobre las Sentencias citadas (SSTJCEE Stauder, International Handelgesselschaft, Nold, Rutili Hauer, y N. Panasonic, entre otras), acúdase al seguimiento que de la cuestión nos propone D. RuIz-JARABO, en su trabajo "Los derechos humanos en la Jurisprudencia del Tribunal de las Comunidades Europeas", en Poder Judicial. N. Especial. VI, CEJ, 1989.

En particular, la temática de la extranjería en el Derecho constitucional español ha sido tratada también reciente y solventemente en esta última obra (Estudios en Homenaje al Prof. G. de Enterría). Véanse concretamente las contribuciones que firman (Tomo II de la misma) los Profs. I. BORRAJO ("El status constitucional de los extranjeros»), R. Alonso ("Derechos fundamentales y Comunidades Europeas») y R. GARCIA MACHO ("EI derecho de asilo y del refugiado en la Constitución Española»).

De la creciente importancia de la ordenación jurídica del asilo y del refugio nos da cuenta el exhaustivo análisis desplegado por D. LóPEZ GARRIDO desde la perspectiva inconstitucional, española y comparada (especialmente relevante en lo atinente a Alemania $y$ a los efectos de Schengen 1985 y 1990). Véase así su obra (El derecho de asilo. Madrid, Ed. Trotta/ INSS, 1991), conteniendo interesantes Anexos de legislación 
internacional e interna, jurisprudencia del TC relativa a extranjería (SSTC 107/82; 90/83; 115/87; y 8/90); del Tribunal Supremo y de la Audiencia Nacional, así como otros documentos y datos de índole estadística.

En fin, debe recordarse que hasta la fecha el TC no ha acometido problemas de reforma y revisión de la Constitución, ni ha sido instado, vía consulta, a ejercitar la competencia previa a la ratificación de un Tratado que contenga estipulaciones verosímilmente contrarias a la Constitución (arts. $95 \mathrm{CE}, 78 \mathrm{LOTC}, 157 \mathrm{RCD}$ y $147 \mathrm{RS}$ ), ni ha sido tampoco llamado a pronunciarse sobre el tema, mucho más espinoso, de la constitucionalidad de una concreta iniciativa de reforma de la CE, eventualidad ésta carente de apoyo positivo expreso, pero pese a ello presente, cuando al menos, al nivel de la especulación doctrinal. 